\title{
Applying a BP Neural Network Approach to the Evolution Stage Classification of China Rift Lakes
}

\author{
T. Zhang, W. H. Zeng, and F. L. Yang
}

\begin{abstract}
The evolution stage classification which contains adolescence, adulthood, and old age of China rift lakes was constructed by using BP neural network model. In this paper, the model was applied to eleven lakes from Yunnan Plateau Lakes region and the middle and lower reaches of the Yangtze River plain. Through the selection of training samples, test samples and optimal number of hidden layer nodes to determine, the precision of BP neural network classification is supposed suitable for evolution stage classification of rift lakes. According to the classification results, dianchi lake is an old age lake, erhai lake, chenghai lake, xingyun lake, yilong lake, qilu lake, yangzong lake and chaohu lake are all in adulthood, and fuxian lake, lugu lake and poyang lake are in adolescence.
\end{abstract}

Index Terms-Evolution stage classification, rift lakes, BP neural network.

\section{INTRODUCTION}

The lifetime of a lake ranges from thousands of years to millions of years, and can be divided into several stages: adolescence, adulthood, old age, and decline (adolescence (Lugu Lake), adulthood (Erhai Lake), old age (Dianchi Lake), and the decline phase (Lop Lake)). From the formation process of a rift lake, which forms due to large-scale fault activity, the subsidence of the lake basin changes rapidly and the basin is mainly filled with accumulated coarse sediments. When the subsidence gradually slows down and a lacustrine delta develops, the lake reaches adulthood stage. At this time, the lake changes from deep to shallow and the main sediments become fine-grained. In addition, aquatic plants and phytoplankton increase to large numbers. Throughout the old age phase, a large amount of sediment fills up the lake basin due to greater sedimentation causing the water area to become narrow and shallow until, finally, a swamp lake evolves [1], [2].

During the long-term evolution stage, lakes (adolescence, adulthood, old age) of different types may have diverse vital signs and face different environmental problems, especially showing obvious stage characteristics and differences based on ecological and environmental problems in different stages of evolution [3]. Therefore, for each evolution stage in different lakes, we should propose appropriate governance and recovery strategy to keep the lake in a

Manuscript received April 24, 2014; revised August 21, 2014.

T. Zhang and W. H. Zeng are with State Key Laboratory of Water Environment Simulation, School of Environment, Beijing Normal University, Beijing, China (e-mail: zhangting08@ieecas.cn; zengwh@bnu.edu.cn).

F. L. Yang is with Yunnan Institute of Environmental Science, Kunming, China (e-mail: yfl@yies.org.cn). healthy state, and these can provide reference for the effective governance of the numerous lakes in the world [4]. However, researchers in lake evolution still not give a clear evolution stage classification of China rift lakes at present.

BP neural network as one of the most widely used neural network model, it has been used in diverse applications in pattern recognition, classification, forecasting, manufacturing, optimization and so on [5]. Compared with the traditional algorithms, it has advantages in fast processing speed and robustness. At the same time, BP neural network is able to learn incomplete data, deal with nonlinear problems and when trained, it could carry out predictions satisfactorily [6]. This paper put forward BP neural network method to the evolution stage classification of China rift lakes, and the results were analyzed show that the algorithms are effective.

\section{MATERIAL AND METHODS}

\section{A. Study Area}

Yunnan Plateau Lakes regions are the most typical rift lakes in China. They formed in earlier era, mostly in the late Pliocene to early Quaternary. The most famous lakes of this region are Dianchi Lake $\left(24^{\circ} 40^{\prime}-25^{\circ} 02^{\prime} \mathrm{N}, 102^{\circ} 36-102^{\circ} 47^{\prime}\right.$ E), Erhai Lake $\left(25^{\circ} 36^{\prime}-25^{\circ} 58^{\prime} \mathrm{N}, 100^{\circ} 05^{\prime}-100^{\circ} 17^{\prime} \mathrm{E}\right)$ and Fuxian Lake $\left(24^{\circ} 21^{\prime}-24^{\circ} 38^{\prime} \mathrm{N}, 102^{\circ} 49^{\prime}-102^{\circ} 57^{\prime}\right.$ E), and these three lakes roughly represent the evolution stage of old age, adulthood and adolescence. The remaining unknown period of six lakes, including Cheng Hai Lake $\left(26^{\circ} 27^{\prime}-26^{\circ} 38^{\prime} \quad \mathrm{N}, \quad 100^{\circ} 38^{\prime}-100^{\circ} 41^{\prime} \quad\right.$ E), Lugu Lake $\left(27^{\circ} 41^{\prime}-27^{\circ} 45^{\prime} \mathrm{N}, 100^{\circ} 45^{\prime}-100^{\circ} 50^{\prime} \mathrm{E}\right)$, Xingyun Lake $\left(24^{\circ} 21^{\prime}-24^{\circ} 38^{\prime}\right.$ N, $102^{\circ} 49^{\prime}-102^{\circ} 57^{\prime}$ E), Yilong Lake $\left(23^{\circ} 38^{\prime}-23^{\circ} 42^{\prime} \quad \mathrm{N}, \quad 102^{\circ} 30^{\prime}-102^{\circ} 38^{\prime} \quad\right.$ E), Qilu Lake $\left(24^{\circ} 08^{\prime}-24^{\circ} 13^{\prime} \mathrm{N}, \quad 102^{\circ} 43^{\prime}-102^{\circ} 49^{\prime}\right.$ E), Yangzong Lake $\left(24^{\circ} 51^{\prime}-24^{\circ} 58^{\prime} \mathrm{N}, \quad 102^{\circ} 58^{\prime}-103^{\circ} 01^{\prime} \mathrm{E}\right)$ are also typical rift lakes. Furthermore, in the middle and lower reaches of the Yangtze River plain, Poyang Lake $\left(28^{\circ} 24^{\prime}-29^{\circ} 46^{\prime} \mathrm{N}\right.$,

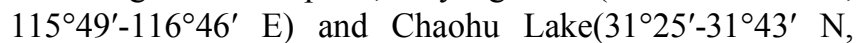
$\left.117^{\circ} 16^{\prime}-117^{\circ} 5^{\prime} \mathrm{E}\right)$ are also typical rift lakes. Therefore, we selected the above lakes as samples.

\section{B. Study Methodology}

\section{1) BP neural network}

BP Neural Network is one of the most widely used neural networks. It is a multilayer neural network which contains input layer nodes, output layer nodes and one or more layers of hidden nodes. The information transfers from nodes to nodes of different layers, and the degrees of the connections are controlled by the connection weights that are adjusted on the basis of data by training [7], [8]. When the connection 
weights change, the performance of the entire BP neural network will be changed.

\section{2) Sample collection and tag}

When using B P Neural Network to get the Evolution Stage Classification of China Rift Lakes, firstly, we need to collect enough training samples including the known and unknown evolution stage lake samples. The known part is composed of adolescence (Fuxian Lake and Poyang Lake), adulthood (Erhai Lake), and old age (Dianchi Lake). Next is the sample tag. Neural network training process is generally divided into two types, supervised and unsupervised manner. From the perspective of improving the classifier performance, we designed a supervised classification using neural networks manner. What is more, sample tag needs to be added sample evolution stage period determined by human, of those above known samples. Therefore, we collected samples for classification mark, so we could train the neural network better.

\section{3) Characteristic extraction}

When we classify the evolution stage of rift lakes, there always exist a large number of original data. Those samples are in a high-dimensional space, so we need such an approach like mapping or transformation to show the samples in a low dimensional space. This process is called Characteristic extraction. Original input message of this paper is based on the analysis of both the driving factors of lake evolution and the indicators reflected the evolution characteristics of lakes. There are a total of 30 indicators we choose. And these data are mainly from 1992 to 2010 of Dianchi Lake, Erhai Lake and Fuxian Lake, 1994-2012 of Poyang Lake, 1986-1995 and 2000-2008 of Chaohu Lake, and all the data for each index are of 18 consecutive years .Due to the incoherence of other lakes, we just get 2005-2012 data of Cheng Hai Lake, Lugu Lake, Xingyun Lake, Yilong Lake, Qilu Lake, Yangzong Lake for evolution stage classification of lakes. Table I shows the primary indicators of lake evolution stage classification.

TABLE I: PRIMARY INDICATORS OF LAKE EVOLUTION STAGE CLASSIFICATION

\begin{tabular}{|c|c|}
\hline Type & Primary indicators \\
\hline $\begin{array}{l}\text { Chemical } \\
\text { indicators }\end{array}$ & $\begin{array}{l}\text { chemical oxygen demand(COD), ammonia } \\
\text { nitrogen }\left(\mathrm{NH}_{4}^{+}-\mathrm{N}\right) \text {, total phosphorus(TP), } \\
\text { total nitrogen }(\mathrm{TN})\end{array}$ \\
\hline $\begin{array}{l}\text { Physical } \\
\text { indicators }\end{array}$ & $\begin{array}{l}\mathrm{pH} \text {, transparency, water temperature, depth, area, } \\
\text { salinity, eutrophication, water type, } \\
\text { degree of water pollution, eutrophication index }\end{array}$ \\
\hline $\begin{array}{l}\text { Biological } \\
\text { indicators }\end{array}$ & chlorophyll a, phytoplankton, zooplankton, benthos \\
\hline $\begin{array}{l}\text { Sediment } \\
\text { indicators }\end{array}$ & $\begin{array}{l}\text { deposition rate, total organic carbon, total nitrogen, total } \\
\text { phosphorus, sediment heavy metals (lead, cadmium, } \\
\text { mercury, chromium, arsenic) }\end{array}$ \\
\hline $\begin{array}{l}\text { Socio-econo } \\
\text { mic } \\
\text { indicators }\end{array}$ & land use status, population, GDP \\
\hline
\end{tabular}

The input vectors are those eigenvalues which generally have different dimensions and larger numerical difference, according to the characteristics of neural networks, if we input them directly; they will become very large and difficult to make the network convergence through the accumulator. Therefore it is necessary to normalize the network input vectors. Normalization method used here is shown in formula 1.

$$
x_{\mathrm{i}}^{\prime}=\frac{x_{i}-x_{\min }}{x_{\max }-x_{\min }}
$$

$x_{i}, x_{\mathrm{i}}^{\prime}$ are the values before and after the normalization, and $x_{\max }, x_{\min }$ are the maximum and minimum values before and after the normalization.

\section{4) BP neural network structure}

The study designed a three layer BP feed-forward neural network, and there were three basic layers: an input layer node, hidden layer node and output layer node (Fig. 1).

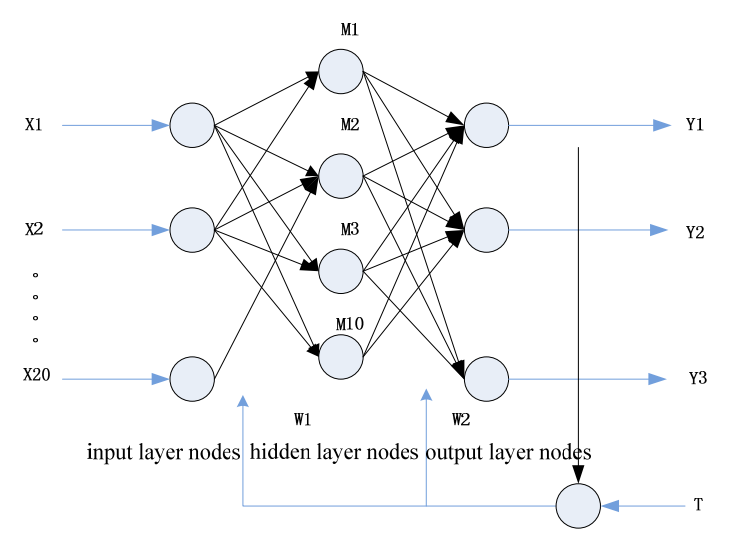

Fig. 1. The general three layer BP feed-forward neural network with one hidden layer

After Characteristic extraction, the BP neural network deleted those redundant, irrelevant eigenvalues, as a result, the number of representative evolution stage classification index of lakes changed from 30 to 20 , and therefore the number of input layer nodes of the neural network was 20 .

There is a direct relationship between the number of hidden layer nodes and neuron number in input layer and output layer, too much or too little will affect the stability of the network. According to Zhang's experimental results [9], we used the following formula 2 as a reference.

$$
N_{H}=\frac{N_{I}+\left(N_{O}, N_{C}\right)_{\mathrm{MAX}}}{2}
$$

$H_{H}, N_{I}, N_{O}, N_{C}$ were hidden layer nodes, the input vector dimension, the output nodes and the target number of categories, respectively. $\left(N_{O}, N_{C}\right)_{\text {MAX }}$ were the maximum value of $N_{O}$ and $N_{C}$. So basing on the above empirical formula, we got the hidden layer nodes were 10 .

On the basis of three lake evolution stages, as adolescence, adulthood and old age, the number of output layer nodes is also three.

\section{RESULTS}

18 consecutive years' data were used for BP neural network training. Fig. 2 reveals the matching probability with respect to the evolution stage (adolescence, adulthood, old age) of four training samples. The classification results show that Dianchi Lake, Erhai Lake, Fuxian Lake and 
Poyang Lake are in old age stage, adulthood stage, and adolescence stage, respectively.
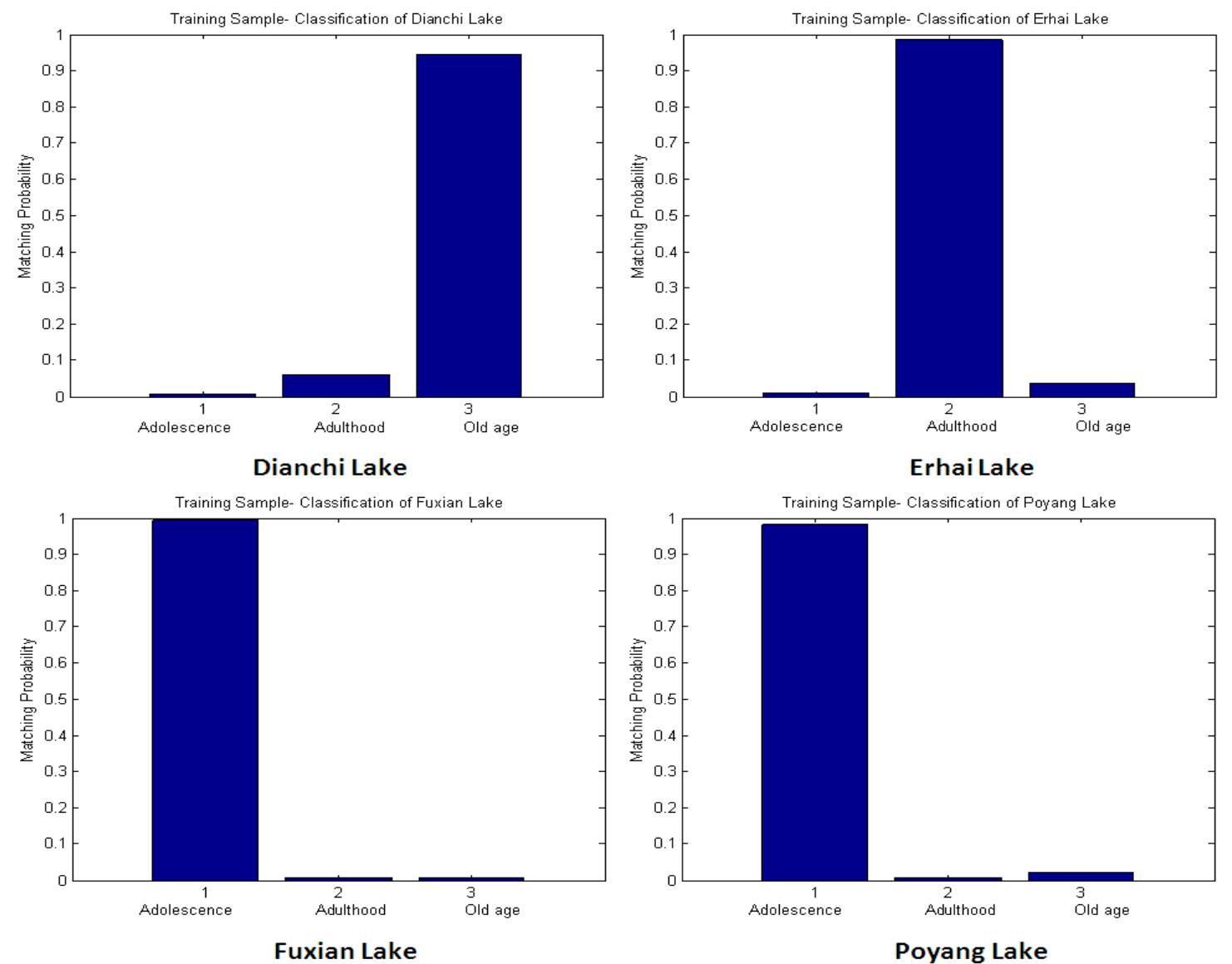

Fig. 2. The matching probability with respect to the evolution stage (adolescence, adulthood, old age) of training samples.
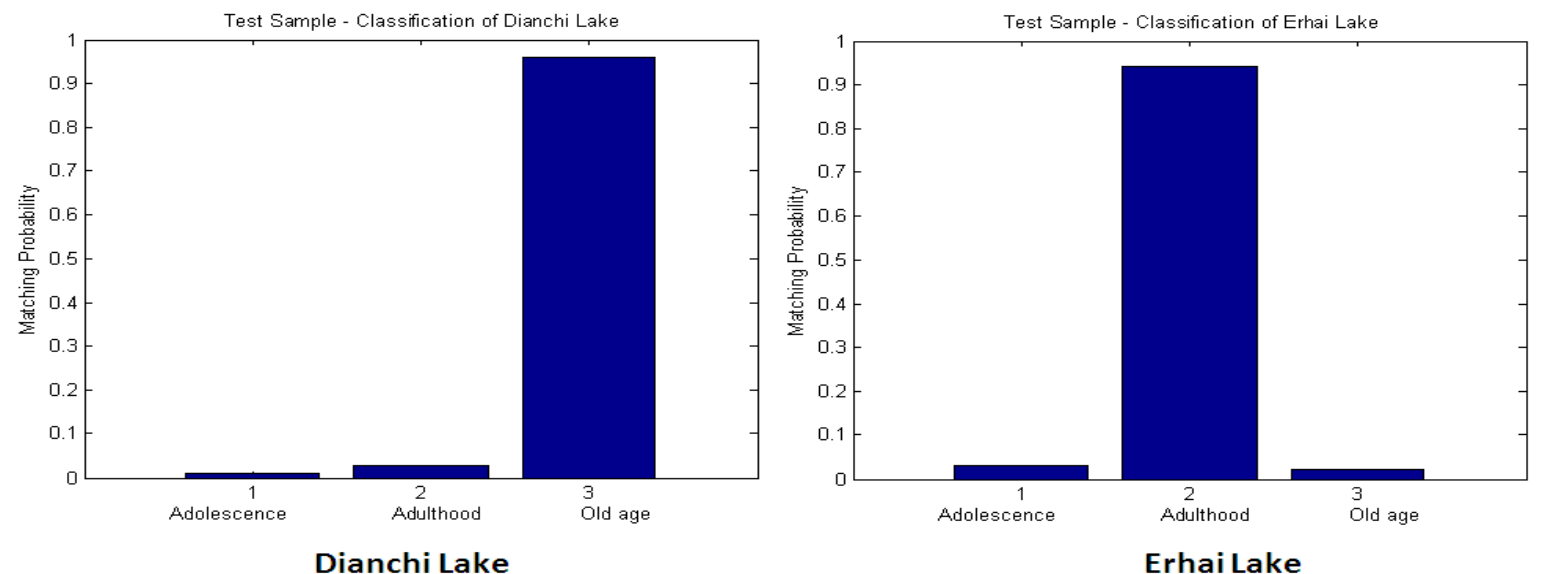

Dianchi Lake
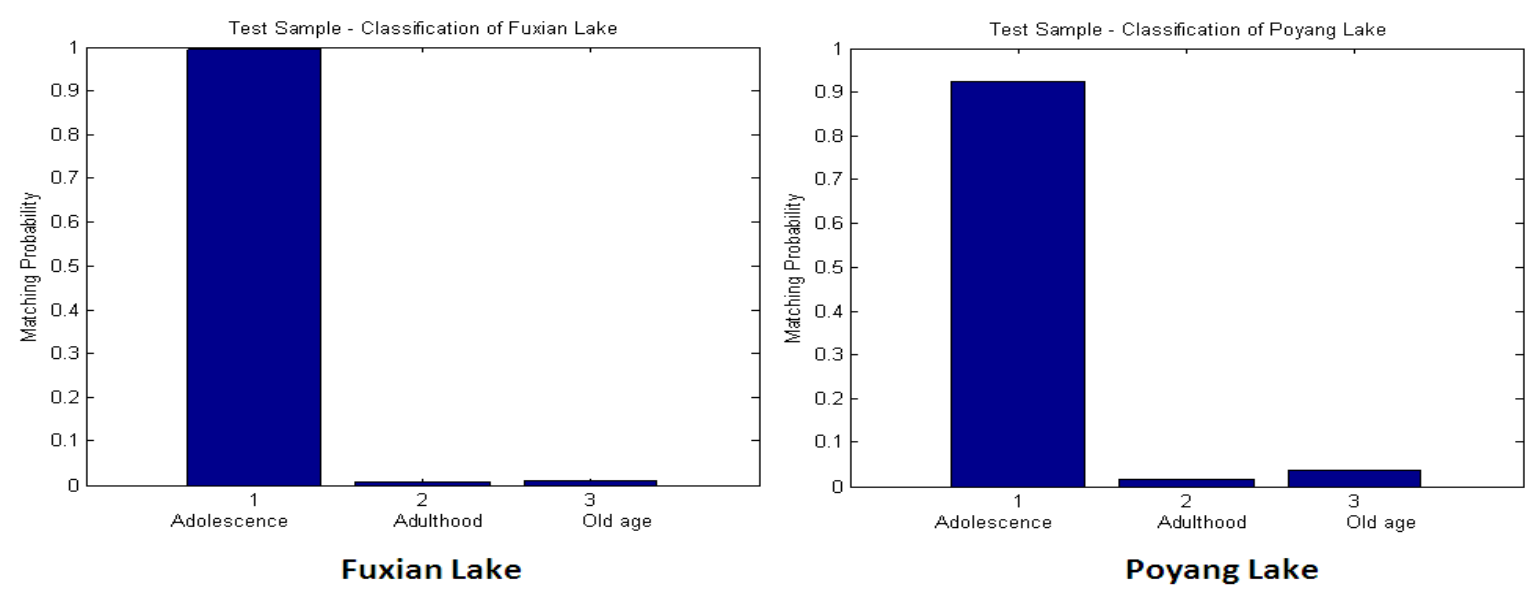

Fig. 3. The matching probability with respect to the evolution stage (adolescence, adulthood, old age) of test samples. 

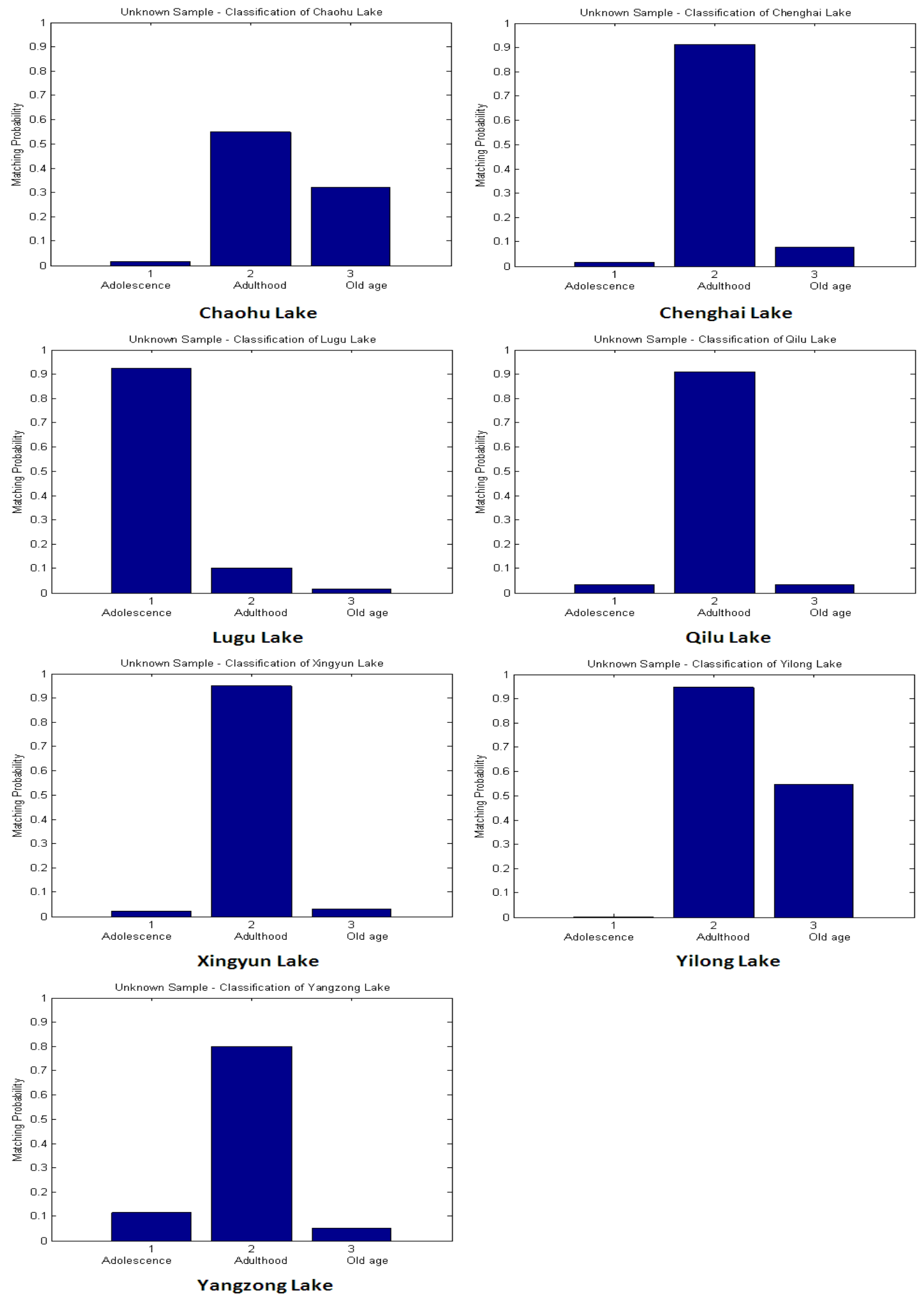

Fig. 4. The matching probability with respect to the evolution stage (adolescence, adulthood, old age) of unknown sample.

Then we randomly selected 4 years data from the 18 years of continuous data as the test samples to verify the classification results. Fig. 3 shows the matching probability with respect to the evolution stage (adolescence, adulthood, old age) of test samples. Test samples of known lakes classification results can match well with the training results, it indicates that BP neural network training is successful; we can use it to classify the evolution stage of other remaining unknown rift lakes.

For those unknown evolution stage lakes, including Chaohu Lake, Cheng Hai Lake, Lugu Lake, Xingyun Lake, Yilong Lake, Qilu Lake, and Yangzong Lake, we used 5 consecutive years' data to classify the evolution stage. Fig. 4 shows that, in addition to Lugu Lake, other lakes are all in the adult stage of evolution, and Lugu Lake is in adolescence stage. Of those lakes, Chaohu Lake and Yilong 
Lake have some differences with other lakes. Although the matching probability of adulthood is obvious, however, the matching probability of old age is also shown in Fig. 4, which means those two lakes are changing from adulthood to old age stage.

\section{CONCLUSION}

Therefore, in this study, BP neural network method was successfully applied to classify the evolution stage of China rift lakes at the study area in the Yunnan Plateau Lakes and the middle and lower reaches of the Yangtze River plain. The method helped in classifying three evolution stages of lakes, including adolescence, adulthood, and old age of eleven China rift lakes by setting up training samples and test samples.

As each evolution stage in different lakes, we should adhere to specific management strategies to keep the lake in a healthy state. So the results are useful for the policy makers around the country and abroad that are making decisions regarding control strategies of environmental problems in other similar lakes. And also the results could be a contribution to the management of water conflicts between human and ecosystems [10], [11].

\section{ACKNOWLEDGEMENTS}

This work was supported by the National Major Scientific and Technological Project of China (NO. 2012ZX07102-002).

\section{REFERENCES}

[1] S. M. Wang and H. S. Dou, The lakes of China, Science Press, Beijing, 1999, pp. 14-20.

[2] T. Zhang, W. H. Zeng, S. R. Wang, and K. Ni, "Temporal and spatial changes of water quality and management strategies of Dianchi lake in southwest China," Hydrol. Earth Syst. Sci., vol. 18, pp. 1493-1502, 2014.

[3] C. Koç, "The effects of the environment and ecology projects on lake management and water quality," Environ. Monit. Assess, vol. 146, pp. 397-409, July 2008.

[4] X. C. Jin, S. R. Wang, and H. Y. X, "Lake ecological security and assessment methodology framework," Research of Environmental Science, vol. 25, no. 4, pp. 357-362, April 2012.

[5] S. Haykin, Neural Networks: A Comprehensive Foundation, New York, USA: McMillan College Publishing Company, 1994, ch. 2.

[6] H. Taghavifar and A Mardani, "Applying a supervised ANN (artificial neural network) approach to the prognostication of driven wheel energy efficiency indices," Energy, vol. 68, no. 15, pp. 651-657, April 2014.

[7] Y. P. Jiang, Z. X. Xu, and H. L. Yin, "Study on improved BP artificial neural networks in eutrophication assessment of China eastern lakes," Journal of Hydrodynamics, Ser. B. vol. 18, pp. 528-532, July 2006.

[8] Y. H. Bao and J. B. Ren, "Wetland landscape classification based on the BP neural network in DaLinor lake area," Procedia
Environmental Sciences, vol. 10, pp. 2360-2366, Xi' an China, ESIAT Press, 2011.

[9] Q. L. Zhang and X. M. Li, "A new method to determine hidden note number in neural network," Journal of Jishou University (Natural Science Edition), vol. 23, no. 1, pp. 89-91, Mar. 2002.

[10] A. Christofides, A. Efstratiadis, D. Koutsoyiannis, G. F. Sargentis, and K. Hadjibiros, "Resolving conflicting objectives in the management of the Plastiras Lake: can we quantify beauty?," Hydrol. Earth Syst. Sci. vol. 9, pp. 507-515, 2005.

[11] Y. P. Cai, G. H. Huang, Z. F. Yang, and Q. Tan, "Identification of optimal strategies for energy management systems planning under multiple uncertainties," Appl. Energ., vol. 86, pp. 480-495, April 2009.

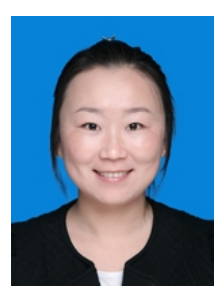

T. Zhang was born in Shaanxi China, 1985. She received her bachelor of science, environmental science from Jilin University, Changchun, China in 2008 and she received her master of science, environmental science at the Institute of Earth Environment, Chinese Academy of Sciences, Xi'an China in 2011, she is a Doctor of Science, environmental science, Beijing Normal University, Beijing, China, up to now.

She has worked in Beijing Environmental Protection Bureau in 2013 as an intern. Her research interests include environmental planning and management and lake pollution management.

She is a member of CSES.

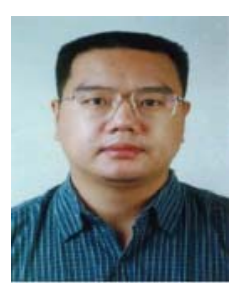

W. H. Zeng was born in Beijing China, 1965. He received his bachelor of engineering, environmental engineering from Tsinghua University, Beijing, China in 1987 and he received his master of Engineering, environmental geology from Beijing Normal University, Beijing, China in 1990, he is a doctor of Engineering, environmental engineering, Tsinghua University, Beijing, China, 1996.

He held various positions in Beijing Normal University as a lecturer, postdoctoral, associate professor, and professor. And now he is an institute director of school of environment in Beijing Normal University, Beijing, China. His Research interests include environmental systems engineering, environment simulation, optimization and integration management, and environmental impact assessment.

Prof. Zeng is a member of CSES, and he is also a vice secretary general of Environmental Planning Professional Committee of CSES.

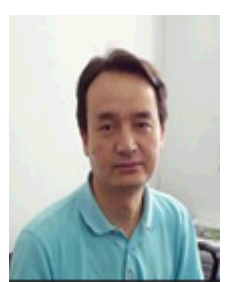

F. L. Yang was born in Kunming, China in 1970 $\mathrm{He}$ received his bachelor of engineering, environmental engineering from Kunming University of Science and Technology, Kunming, China in 1992 and He received his master of Engineering, environmental engineering from Kunming University of Science and Technology, Kunming, China, 2008.

$\mathrm{He}$ held various positions in Yunnan Institute of Environmental Science as an engineer, senior engineer, director of engineering research center, and now he is the vice president of Yunnan Institute of Environmental Science, Kunming, China. His research interests include environmental engineering, river and lake pollution control, and pollution of lake wetland restoration.

Mr. Yang is a member of CSES. 